DOI 10.22455/2541-8297-2017-4-225-232

УДК 17.51

\title{
Неизвестный перевод Андрея Белого
}

\author{
Д.О. Ториилов
}

Аннотация: Неопубликованный текст Андрея Белого является чуть ли не уникальным образцом его переводов. Выполненный во время тесного сотрудничества с В.Э. Мейерхольдом, перевод статьи К. Зервоса о постановке «Ревизора» проливает дополнительный свет на представления Белого о связи языкового и визуального как в его творчестве, так и в исследовательской деятельности.

Ключевые слова: Андрей Белый, Гоголь. Мейерхольд, теория и практики перевода, языковое и визуальное.

Информация об авторе: Торшилов Дмитрий Олегович, к.ф.н., доцент кафедры классической филологии Института восточных культур и античности Российского государственного гуманитарного университета; Москва. E-mail: dmitry.torshilov@gmail.com

Собственные произведения Андрея Белого всегда задействуют такие ресурсы родного языка, которые делают их переводимыми на другие языки разве что в прямом словарном смысле, с утратой их специфических достоинств; с этим связано другое обстоятельство - сам Белый, «скиф», никогда не переводил с иностранных языков; в списке его сочинений, в отличие от большинства его ближайших спутников в русской литературе, раздел «переводы» остается пустой. «Из всего поколения старших символистов Андрей Белый наименее культурен [...] Как-то не представляется, что он бывал в Лувре, читал Гомера...», - писал Н.С. Гумилев [10, с. 19].

Из этого правила известны только два или три небольших исключения. В сентябре 1913 г., вскоре после признания себя учеником Р. Штейнера, Белый переводит с немецкого фрагмент из его драмы-мистерии «Врата посвящения» (в переводе Белого «У врат посвящения»; опубликован: [16], об истории создания см.: [12]). Согласно сообщению С.В. Казачкова, в частном собрании хранится сделанный Белым перевод курса лекций Р. Штейнера «Бхагавадгита и послания апостола Павла» [13, с. 77]. Возможно, это все же конспект или пересказ, а не собственно перевод. Наконец, в конце мая 1927 г. Белый переводит с французского хвалеб- 
ный отзыв о мейерхольдовской постановке «Ревизора» известного художественного критика (грека по происхождению) Кристиана (Христоса) Зервоса (1889-1970). Зервос и его журнал «Cahiers d'art» были тесно связаны не только с П. Пикассо (как повторяет Белый), но и с А. Матиссом, Ж. Браком, впоследствии с Ж. Миро, М. Шагалом, Ф. Леже.

О датировке перевода говорит письмо Белого П.Н. Зайцеву от 9 июня 1927: «Еще: думаю, что в Никитинский сборник о Мейерхольде хорошо было бы напечатать маленькую статью о "Ревизо$p e$ ", появившуюся в органе Пика́ссо (по-французски); она - коротка, но ее очень стоило бы напечатать как мнение органа Пика́ссо (да и самого Пика́ссо), считающего, что "Ревизор" - чудо сценического воплощения; будучи в Тифлисе, я перевел эту статейку и оставил Мейерхольду, который хотел выслать Вам» $[11$, c. 389]. Упоминает Белый его и в «Ветре с Кавказа», очерке о своем летнем путешествии 1927 г.: «Я что-то нигде не наткнулся на такого рода разбор; нет, - наткнулся: в французском журнале, в журнале... Пикассо... Там высказались: “Ревизор” Мейерхольда есть новая главка в истории изобразительности» [1, с. 86].

В Тифлисе, согласно «Ракурсу к дневнику» [5, с. 498], Белый вместе с К.Н. Бугаевой останавливался как раз у Мейерхольдов; это было 19-24 мая 1927 г. В эти дни выполнен и публикуемый перевод. Экземпляр журнала, с которого он сделан, надо полагать, также нашелся у Мейерхольдов. «Никитинским сборником» Белый называет сборник «Гоголь и Мейерхольд», вышедший в издательстве «Никитинские субботники» в конце того же 1927 г. и открывающийся его одноименной статьей $[8$, с. 9-38; переиздана: 4, c. 369-386].

Это период самого активного сотрудничества Белого с Мейерхольдом и его театром. Он начинается осенью 1926 г., когда Мейерхольд предлагает переработать первый том романа «Москва» в драму для постановки в ГосТИМ'е [5, с. 492-495]; зимой Белый работает над этой драмой, посещает репетиции «Ревизора», в феврале пишет упомянутую статью «Гоголь и Мейерхольд» (подробнее об отношениях Белого с Мейерхольдом см., в частности, [3]).

По переводу драмы-мистерии Штейнера, выполненному верлибром, все же нельзя было судить, как Белый переводил бы обычную прозу; ведь специфика его стиля - ритмизация, обилие неологизмов, прихотливый синтаксис и интонация сказа - свойственна вовсе не только его художественной прозе, но и статьям, и переписке; по некоторым воспоминаниям, она была отчетливо слышна даже в его устной речи [7, с. 335]. При этом перевод статьи Зервоса сделан вовсе не «языком Андрея Белого». К сожалению, остается без ясного ответа обратный вопрос, — как проявля- 
лась стилистика Белого, когда он писал не на родном языке, потому что написанное им по-немецки не опубликовано (например, письмо М. Бауэру, см. [6]; неясно, аутентична или сделана при помощи переводчика его немецкая статья «Die Anthroposophie und Rußland», см.: [19], [14]).

Относительно содержания публикуемой статьи нужно сказать, что Зервос, писавший в основном о художниках, в постановке «Ревизора» видит прежде всего зрелище и даже просто картину: «эффекты, реализуемые цирком и кинематографом», «красочные эффекты», «несравнимый колорит», «три захватывающих и прекрасных картины»; режиссер вообще сравнивается с «иллюстратором», которого не надо упрекать за «свободу обращения с текстом и его духом». Белому, проза которого в 1920-1930-е гг. особенно экфрастична, полна выполненных с преувеличенной точностью и детализацией описаний (ср.: [9, с. 793-795; 15; 17; 18, с. 357]), оказался близок этот парадокс текста как картины. Эту линию, «изобразительность Гоголя», развивает третья глава его написанного впоследствии «Мастерства Гоголя» [2], которой он отчасти обязан Мейерхольду и Зервосу.

Автограф перевода хранится в РО Центральной научной библиотеки СТД РФ. Оригинал: Christian Zervos Le "Revisor" de Gogol réalisé par Meyerhold // Cahiers d'art. 1927. № 2. P. 75-76. Публикатор благодарит В.П. Нечаева за сохранность редкого текста и возможность с ним познакомиться.

Кристиан Зервос

\section{«Ревизор» Гоголя в воплощении Мейерхольда}

\section{Перевод Андрея Белого}

«Ревизор» Гоголя - последнее создание Мейерхольда, чудесного артиста, единственного в своем роде, который сумел в наши дни возвысить искусство постановки до чистого классицизма. Весь мир знает сюжет Гоголя, как кажется, инспирировавший Жана Кокто в его прекрасном романе «Фома Самозванеи» 1 .

Вот этот сюжет: некто приезжает в провинциальный город. Его ошибочно принимают за Ревизора, своего рода контролера провинциальной администрации. Все охвачены паникой, особенно те из чиновников, которые имеют на совести большие или малые проступки.

${ }^{1}$ Роман Ж. Кокто по-русски обычно называют «Самозванец Тома». Был напечатан в «Никитинских субботниках» двумя годами ранее, в 1925 г., в переводе В. Мониной. 
Ложный Ревизор входит в свою роль; он становится причиной смятения погруженных в сон провинциалов, всюду одних и тех же.

Самозванец устрашает всех и покоряет сердца, особенно сердце дочери городничего, предмет вожделений городской молодежи. Потом обман раскрывается, и все оказываются потерпевшими.

Для этой фабулы Мейерхольд дал прекраснейшее сценическое оформление, секретом которого он гениально владеет. Его попытка послужила поводом к многим диспутам в России и даже подверглась жестокой критике со стороны московской прессы.

Театральные критики ему ставят в вину свободу обращения с текстом и в особенности с духом текста, в чем они сильно неправы.

Подобно тому как нельзя требовать, чтобы иллюстратор книги слепо следовал тексту, так же ошибочно отнимать у режиссера право на импровизацию и на внесени своего понимания в дух пьесы.

Мейерхольд воспользовался пьесой Гоголя для выражения своего взгляда на театр. Я, зритель, никогда не хожу в театр: сценическое воплощение пьесы всегда ниже пьесы. Обыкновенно я удовлетворяюсь чтением пьесы и воссозданием ее в себе сообразно с моим собственным пониманием.

Но когда режиссер, или, лучше сказать, тот, кто дает жизнь пьесе, дает мне разрешение ее столь же оригинально, как и поэт, тогда его роль кажется мне нужной и заслуживающей поощрения.

В постановке «Ревизора» Мейерхольд ввел все свои зрелища. Как я уже объяснял в предыдущей статье**, постановка Мейерхольда включает в чисто театральные эффекты еще и эффекты, реализуемые цирком и кинематографом.

В «Ревизоре» эти эффекты возвышены до классического стиля; они оказываются здесь слитыми, воспринятыми и воплощенными так, что производят впечатление цельности.

Это реализовано посредством ни с чем несравнимого колорита, далеко превосходящего художественное чутье его собратьев по искусству.

Вместе с Пикассо в «Ревизоре» я восхищаюсь глубочайшим знанием искусства краски. Ни один художник, ни один постановщик балета (кроме Пикассо) не мог достичь столь точных, совершенных и правдивых красочных эффектов. Посмотрите на боль-

** «Cahiers d'art» № 9 за 1926 год. (Прим. Белого. Сноска с номером * пропущена.)

Статья называлась «Les recherches de Meyerhold» («Поиски Мейерхольда»). 
шое кресло посередине сцены, посмотрите на позы действующих лиц!***

Посмотрите в финале пьесы, когда ложь разоблачена, на искусство, с которым Мейерхольд распределяет внимание на три захватывающих и прекрасных картины.

В таком выявлении конца пьесы Мейерхольд выказал оригинальность. Он порвал с традицией. Традиция заключалась в экспозиции конца пьесы сообразно с указаниями (нарисованными) Гоголя. Мейерхольд выявил конец пьесы сообразно с духом своего понимания и тех требований, которые он себе ставил. Мейерхольд ввел в конец пьесы новый элемент: гротеск. Гротеск в последние годы был использован балетом. Но в балете нет словесного материала, который, будучи противопоставлен пантомиме, увеличивает гротеск. Этот эффект был получен Мейерхольдом посредством картонных манекенов, которые выявляют пластику другого рода и силы, чем пластика живого существа, не могущего оставаться неподвижным достаточно долго для того, чтобы дать полное впечатление гротеска.

Так мы рассматриваем искусство театра. Вот почему в этом обзоре я не говорю ни о чем ином, кроме опыта Мейерхольда.

Это единственный опыт, который меня интересует. Остальные искания теряются в бесконечности нисколько меня не интересующих деталей, потому что в них отсутствует подлинный дух сцены.

Христиан Зервос****

\section{Литература}

1. Андрей Белый. Ветер с Кавказа. М.: Федерация, 1928.

2. Андрей Белый. Мастерство Гоголя. М.; Л.: ГИХЛ, 1934.

3. Из переписки А. Белого: Письма В.Э. Мейерхольду и 3.Н. Райх / Публ. вступ. ст. и комм. Джона Малмстада // Новое литературное обозрение. 2001. № 51. С. 132166.

4. Андрей Бельй. Мастерство Гоголя // Андрей Бельй. Собрание сочинений. Т. IX / Общ. ред., сост., послесловие и комм. Л.А. Сугай. М.: Издательство «Дмирий Сечин», 2013.

5. Андрей Бельй: Автобиографические своды: Материал к биографии. Ракурс к дневнику. Регистрационные записи. Дневники 1930-х годов / Сост. А.В. Лавров и Дж. Малмстад; подг. текста А.В. Лаврова, Дж. Малмстада, Т.В. Павловой, М.Л. Спивак; статьи и коммент. А.В. Лаврова, Дж. Малмстада, М.Л. Спивак // Литературное наследство. Т. 105. М.: Наука, 2016.

\footnotetext{
*** Речь идет о снимках с «Ревизора», приложенных к тексту статьи. Примечание переводчика. (Прим. Белого.)

**** Редактор «Cahiers d'art», органа Пикассо. (Прим. Белого. Другой рукой зачеркнуто «органа Пикассо», добавлено «Paris, 1927, № 2».)
} 
6. Андрей Бельй. Письмо Михаилу Бауэру / Подг. текста, прим. М.Л. Спивак, пер. с нем. Х. Шталь // Арабески Андрея Белого. Жизненный путь. Духовные искания. Поэтика / Ред.-сост. К. Ичин, М.Л. Спивак. М.; Белград, 2017. С. 225-261.

7. Берберова Н.Н. Из книги «Курсив мой» // Воспоминания об Андрее Белом / Сост. В.М. Пискунов. М.: Республика, 1995. С. 326-340.

8. Гоголь и Мейерхольд: Сборник литературно-исследовательской ассоциации ЦДРП / Под. ред. Е.Ф. Никитиной. М.: Никитинские субботники, 1927. 88 с.

9. Глухова Е.В., Торшилов Д.О. Проза Андрея Белого // Русская литература 1920 1930-х годов. Портреты прозаиков: В 3 т. Т. 1. Кн. 2. М.: ИМЛИ РАН, 2016. С. $768-$ 806.

10. Гумилев Н.С. Соч.: В 3 т. Т. III. Письма о русской позии. М.: Художественная литература, 1991.

11. Зайцев П.Н. Воспоминания / Сост. М.Л. Спивак, вступ. статья, комм. М.Л. Спивак, Дж. Малмстада и др. М.: Новое литературное обозрение, 2008.

12. Казачков C.В. «В “Весах» сентября...» // Литературное обозрение. 1995. № 4/5 (252). C. $72-73$.

13. Казачков C.B. «Медитацией укрепленные мысли...» // Андрей Белый: автобиографизм и биографические практики / Ред.-сост. К. Кривеллер, М.Л. Спивак. СПб.: Нестор-История, 2015. С. 27-79.

14. Майдель Р. фон, Безродный М.В. К переводу статьи Белого «Die Anthroposophie und Rußland» на русский язык // Новое литературное обозрение. 1994. № 9. C. $161-167$.

15. Николеску T. Белый и экспрессионизм // Андрей Белый в изменяющемся мире. К 125-летию со дня рождения. М.: Наука, 2008. С. 441-451.

16. Штейнер Р. У врат посвящения / Пер. Андрея Белого. Публ., прим., послесловие С.В. Казачкова // Литературное обозрение. 1995. № 4/5 (252). С. 69-71.

17. Торшилов Д.О. Зрительное в языке: методы анализа визуального ряда произведений литературы в работах А. Белого 1916-1934 гг. // Труды РАШ. Вып. 3. М., 2005. C. $120-165$.

18. Шулова Я.А. «Петербург» и «Москва» А. Белого (вопросы генезиса поэтики). СПб.: Издательство СПбГПУ, 2009.

19. Andrej Bjely. Die Anthroposophie und Rußland // Die Drei. Monatsschrift für Anthroposophie und Dreigliederung. 1922. № 7. S. 26-38. № 8. SS. 45-57.

\section{References}

1. Andrey Bely. Veter s Kavkaza [Wind from the Caucasus]. Moscow, Federatsiia Publ., 1928. (In Russ.)

2. Andrei Belyi. Masterstvo Gogolia [Mastery of Gogol]. Moscow; Leningrad, Gosudarstvennoe izdatel'stvo khudozhestvennoi literatury Publ., 1934. (In Russ.)

3. Iz perepiski A. Belogo: Pis'ma V.E. Meierkhol'du i Z.N. Raikh [From the Correspondence of A. Bely: Letters to V.E. Meyerhold and Z.N. Raich], publ. vstup. st. i komm. Dzhona Malmstada. Novoe literaturnoe obozrenie, 2001, no 51, pp. 132-166. (In Russ.)

4. Andrei Belyi. Masterstvo Gogolia [Mastery of Gogol]. Andrei Belyi. Sobranie sochinenii. T. IX, Obshch. red., sost., posleslovie i komm. L.A. Sugai. Moscow, Dmirii Sechin Publ., 2013. (In Russ.)

5. Andrei Belyi. Avtobiograficheskie svody: Material k biografii. Rakurs $k$ dnevniku. Registratsionnye zapisi. Dnevniki 1930-kh godov [Autobiographical Codes: Material for a Biography. Perspective to the Diary.Registration Records. The Diaries of the 1930s], Sost. A.V. Lavrov i Dzh. Malmstad; podg. teksta A.V. Lavrova, Dzh. Malmstada, T.V. Pavlovoi, 
M.L. Spivak; stat'i i komment. A.V. Lavrova, Dzh. Malmstada, M.L. Spivak. Literaturnoe nasledstvo. T. 105. Moscow, Nauka Publ., 2016. (In Russ.)

6. Andrei Belyi. Pis'mo Mikhailu Baueru [Letter to M. Bauer], Podg. teksta, prim. M.L. Spivak, per. s nem. Kh. Shtal'. Arabeski Andreia Belogo. Zhiznennyi put'. Dukhovnye iskaniia. Poetika, Red.-sost. K. Ichin, M.L. Spivak. Moscow; Belgrad, 2017. Pp. 225-261. (In Russ.)

7. Berberova N.N. Iz knigi «Kursiv moi» [From the book "Italic Is My"]. Vospominaniia ob Andree Belom [Memories of Andrei Bely]. Sost. V. M. Piskunov. Moscow, Respublika Publ., 1995. Pp. 326-340. (In Russ.)

8. Gogol' i Meierkhol'd: Sbornik literaturno-issledovatel'skoi assotsiatsii TsDRP [Gogol and Meyerhold: Collection of the Literary and Research Association of the TsDRP], Pod. red. E.F. Nikitinoi. Moscow, Nikitinskie subbotniki Publ., 1927. (In Russ.)

9. Glukhova E.V., Torshilov D.O. Proza Andreia Belogo [Prose of Andrei Bely]. Russkaia literatura 1920-1930-kh godov. Portrety prozaikov [Russian Literature of 19201930-ies. Portraits of Prose Writers]. V 3 t. T. 1. Kn. 2. Moscow, IMLI RAN Publ., 2016. Pp. 768-806. (In Russ.)

10. Gumilev N.S. Sochineniia v 3-kh tomakh. T. III. Pis'ma o russkoi poezii [Works in 3 Vol. T. III. Letters on Russian Poetry]. Moscow, Khudozhestvennaia literatura Publ., 1991. (In Russ.)

11. Zaitsev P.N. Vospominaniia [Memories], Sost. M.L. Spivak, vstup. stat'ia, komm. M.L. Spivak, Dzh. Malmstada i dr. Moscow, Novoe literaturnoe obozrenie Publ., 2008. (In Russ.)

12. Kazachkov S.V. "V "Vesakh" sentiabria...» [“In the Libra of September..."]. Literaturnoe obozrenie, 1995. no 4/5 (252), pp. 72-73. (In Russ.)

13. Kazachkov S.V. «Meditatsiei ukreplennye mysli...» ["Thoughts, Strengthened by Meditation..."]. Andrei Belyi: avtobiografizm i biograficheskie praktiki [Andrei Bely: Autobiographism and Biographical Practices], Red.-sost. K. Kriveller, M.L. Spivak. SPb.: Nestor-Istoriia Publ., 2015. Pp. 27-79. (In Russ.)

14. Maidel' R. fon, Bezrodnyi M.V. K perevodu stat'i Belogo «Die Anthroposophie und Rußland» na russkii iazyk [To the Translation of Andrei Bely's Article "Die Anthroposophie und Rußland" into Russian]. Novoe literaturnoe obozrenie, 1994, no 9, pp. 161-167. (In Russ.)

15. Nikolesku T. Belyi i ekspressionizm [Bely and Expressionism]. Andrei Belyi v izmeniaiushchemsia mire. K 125-letiiu so dnia rozhdeniia [Andrei Bely in a Changing World. On the 125th Anniversary of his Birth]. Moscow, Nauka Publ., 2008. Pp. 441-451. (In Russ.)

16. Shteiner R. U vrat posviashcheniia [At the Gate of Initiation], Per. Andreia Belogo. Publ., prim., posleslovie S.V. Kazachkova. Literaturnoe obozrenie, 1995, no 4/5 (252), pp. 69-71. (In Russ.)

17. Torshilov D.O. Zritel'noe v iazyke: metody analiza vizual'nogo riada proizvedenii literatury v rabotakh A. Belogo 1916-1934 gg. [Visual in the Language: Methods of Analyzing the Visual Range of Literature in the Works of A. Bely 1916-1934.]. Trudy RASh, 2005, vyp. 3, pp. 120-165. (In Russ.)

18. Shulova Ia.A. «Peterburg» $i$ «Moskva» A. Belogo (voprosy genezisa poetiki) ["Petersburg" and "Moscow" of A. Bely (Questions of the Genesis of Poetics)]. St.-Petersburg, SPbGPU Publ., 2009. (In Russ.)

19. Andrej Bjely. Die Anthroposophie und Rußland [Anthroposophy and Russia]. Die Drei. Monatsschrift für Anthroposophie und Dreigliederung, 1922, no 7, ss. 26-38; no 8, ss. 45-57. (In German) 


\section{Unknown Translation by Andrey Bely}

\section{Dmitry O. Torshilov}

Abstract: Unpublished text by Andrey Bely is a unique example of his translations. Completed during Bely's close cooperation with V.E. Meyerhold, it sheds more light on Bely's ideas about the connection that exists between the linguistic and the visual both in his work and in his studies.

Keywords: Andrey Bely, Gogol. Meyerhold, translation theory, the visual and the linguistic.

Information about author: Torshilov Dmitry O., PhD, Associate Professor, Department of Classical Philology at the Institute of Oriental and Classical Studies, Russian State University for the Humanities; Moscow. E-mail: dmitry.torshilov (a)gmail.com 